\title{
Article
}

\section{The Effects of Red Clover Seed Treatment with Cold Plasma and Electromagnetic Field on Germination and Seedling Growth Are Dependent on Seed Color}

\author{
Anatolii Ivankov ${ }^{1}$, Rasa Zukiene ${ }^{1}{ }^{\circledR}$, Zita Nauciene ${ }^{1}$, Laima Degutyte-Fomins ${ }^{1}$, Irina Filatova ${ }^{2}$, \\ Veronika Lyushkevich ${ }^{2}$ and Vida Mildaziene ${ }^{1, * \text { (D) }}$ \\ 1 Faculty of Natural Sciences, Vytautas Magnus University, Vileikos str. 8, 44404 Kaunas, Lithuania; \\ anatolii.ivankov@vdu.lt (A.I.); rasa.zukiene@vdu.lt (R.Z.); zita.nauciene@vdu.lt (Z.N.); \\ laima.degutyte-fomins@vdu.lt (L.D.-F.) \\ 2 B. I. Stepanov Institute of Physics, National Academy of Sciences of Belarus, 220072 Minsk, Belarus; \\ filatova@presidium.bas-net.by (I.F.); v.lyushkevich@ifanbel.bas-net.by (V.L.) \\ * Correspondence: vida.mildaziene@vdu.lt
}

Citation: Ivankov, A.; Zukiene, R.; Nauciene, Z.; Degutyte-Fomins, L.; Filatova, I.; Lyushkevich, V.; Mildaziene, V. The Effects of Red Clover Seed Treatment with Cold Plasma and Electromagnetic Field on Germination and Seedling Growth Are Dependent on Seed Color. Appl. Sci. 2021, 11, 4676. https://doi.org/ 10.3390/app11104676

Academic Editors: Gyungsoon Park and Henrike Brust

Received: 15 April 2021

Accepted: 18 May 2021

Published: 20 May 2021

Publisher's Note: MDPI stays neutral with regard to jurisdictional claims in published maps and institutional affiliations.

Copyright: (c) 2021 by the authors. Licensee MDPI, Basel, Switzerland. This article is an open access article distributed under the terms and conditions of the Creative Commons Attribution (CC BY) license (https:/ / creativecommons.org/licenses/by/ $4.0 /)$.
Featured Application: The results of this study have the potential for application in agriculture for increasing the production of red clover biomass.

Abstract: This study aimed to estimate the effects of cold plasma (CP) and electromagnetic field (EMF) treatment of red clover (Trifolium pratense) seeds with different coat colors on germination kinetics, the content of seed phytohormones, and the growth of seedlings. Seeds of red clover cultivar 'Arimaiciai' were treated with radio-frequency EMF or capacitively coupled low-pressure $\mathrm{CP}$ for different durations. There were no differences in germination kinetics between yellow, brown, and dark purple seeds in control, but the germination rate of seeds treated with CP and EMF depended on seed color: The germination of yellow seeds was stimulated stronger compared to dark purple and brown seeds, and EMF did not stimulate germination in brown seeds. The content of phytohormones in control seeds and the shift in their amount induced by seed treatments were also strongly dependent on seed color. No relationship was found between the effect on germination kinetics and changes in phytohormone levels. In the control, seedlings growing from the yellow seeds were heavier, and the number of root nodules was 12.5 times larger compared to seedlings of dark purple seeds. Seed treatments with CP and EMF significantly increased the number of root nodules, and this effect was stronger in seedlings from dark purple seeds compared to those from yellow seeds.

Keywords: cold plasma; electromagnetic field; germination; phytohormones; red clover; root nodulation; seed color; seedling growth

\section{Introduction}

Effects of pre-sowing seed treatments with physical stressors, such as non-thermal or cold plasma (CP) and electromagnetic fields (EMF), are under intensive investigation due to their potential as innovative technologies applied in sustainable agriculture [1-6]. It has been reported that such treatments can improve the agricultural performance of various crops, including stimulating germination and seedling growth [7-16], and increasing seed yield [11,13] and disease and stress resistance $[8,13,14]$. The response of seeds to pre-sowing treatments depends on a large variety of factors, such as technical parameters of used experimental devices and treatment conditions [1-6], as well as plant species, seed coat structure, and seed physiological state, which depends on dormancy type, time of seed storage after harvesting, etc. $[10,15,16]$. In addition, most plant species show a continuous intra-individual variation for seed mass, seed morphology [17] causing 
differences in physiological (e.g., germination) traits and plant growth. Therefore, seed development is not temporally uniform in any given population, even when plants are grown in identical environments [18]. Unavoidably, seed heterogeneity enhances the scatter of the experimental results. Seed heteromorphism is considered as an adaptive plant strategy because seed morphs differ in their ecological behavior and such differences are favorable for survival of populations helping the plants cope with spatio-temporal variability of habitats (in contrast, seed uniformity is valued in agriculture). It has been demonstrated that the ability to germinate differs within a population of seeds heterogeneous by size, shape, weight, or color [18]. However, at present, little is known about impact of natural seed heteromorphism on the effects of seed treatments with $\mathrm{CP}$ and EMF although such information is of importance for the development of the reliable agrobiotechnologies based on plasma and EMF effects.

In this respect, variation in the properties of the seed coat should also be considered. Seed coat comprises the structural barrier for seed interaction with any external factor, protects plant embryo from damaging effects, regulates gas, and water exchange, and is involved in germination control. Depending on plant species, seed coats can regulate seed dormancy $[19,20]$. The seed coat's structure and coloration are particularly important for legume seeds that belong to a physical type of dormancy [21]. The presence of pigments and non-colored phenolic compounds can restrict germination since they make the seed coat harder or less permeable [22-24]. These compounds are essential for antioxidant defense (e.g., UV protection); thus, they could interact with free radicals, including those attacking seed surface upon exposure to CP [25]. It has been shown that the number of paramagnetic centers in Norway spruce seeds is increased after seed treatment with CP and EMF, indicating the production of stable organic radicals, most possibly, in a seed coat [26]. The dependence of similar CP-induced changes in radish seed EPR signal on seed color has been reported recently, indicating that the interaction of compounds in the seed coat with plasma particles may differ in seeds of different colors [27,28].

Red clover (Trifolium pratense) is characterized by a considerable variation in seed color with monochrome yellow or purple as primary colors. However, the majority of seeds have an intermediate color due to various proportions of the two primary colors, so that seeds in each lot can be classified into 5 classes by color [29]. The brown color of red clover seeds was considered a hallmark of aging [30]. It has been reported that color of seed coat is an indicator of red clover seed quality and seedling growth ability. The germination parameters of bright yellow seeds were better, and their seedlings grew faster [30] and were more resistant to salt stress [31] compared to seedlings from dark purple seeds.

Since germination and growth of red clover can be strongly stimulated by pre-sowing seed treatment with CP and EMF [16], in this study we aimed to compare the effects of such seed treatments on the germination of red clover seeds separated into three colors: bright yellow, dark purple, and brown. We have reported recently that CP and EMF treatments stimulate growth of red clover roots and nodulation [32], and in this study the effects on nodulation were compared in seedlings from yellow and dark purple seeds grown in rhizoboxes for 5 weeks. It was hypothesized that alterations in phytohormones trigger different germination rates in heteromorphic seeds of certain plant species [18]. Therefore, we estimated the content of seed phytohormones in differently colored red clover seeds as well as shift in the amount of phytohormones induced by CP and EMF treatments.

\section{Materials and Methods}

Red clover seeds of the variety 'Arimaiciai' harvested in 2018 were received from the Institute of Agriculture, Lithuanian Research Centre for Agriculture and Forestry, Lithuania. Seeds were stored in sealed bags in ventilated seed chambers at $3{ }^{\circ} \mathrm{C}$ temperature and were visually checked for quality before the experiment. From the seed lot with a characteristic mixed color pattern (Figure 1a), seeds of three colors-yellow, brown, and dark purple (Figure $1 \mathrm{~b}$, bottom to top) -were manually selected into separate groups, while all seeds with the intermediate coloration were eliminated from the experiment. All groups 
of seeds, including the original ones, were subjected to digital color code measurement using ColorFlex EZ spectrophotometer (HunterLab) in three-dimensional coordinates [33], i.e., $\mathrm{L}^{*}$ (lightness), $\mathrm{a}^{*}$ (red-green), $\mathrm{b}^{*}$ (yellow-blue), in the CIE $1976 \mathrm{~L}^{*} \mathrm{a}^{*} \mathrm{~b}^{*}$ (CIELAB) color space, using color standard $L^{*} 52.9 ; a^{*} 24.7 ; b^{*} 16.0$. The color code detected for the original seed lot was: $L^{*} 49.4 ; a^{*} 5.8 ; b^{*} 27.4$, while the seed groups separated by colors were characterized by the following codes: yellow seeds- $L^{*} 59.0 ; a^{*} 3.5 ; b^{*} 37.5$; brown seeds- $L^{*}$ $46.4 ; a^{*} 6.1 ; b^{*} 24.4 ;$ dark purple seeds: $L^{*} 31.5 ; a^{*} 6.0 ; b^{*} 9.2$. Yellow seeds comprised the major part (53\%) of the seed lot used for this study, while the relative amount of seeds of intermediate color was $30 \%$, and of dark violet color- $15 \%$. Brown seeds comprised only $2 \%$ of the seed lot.

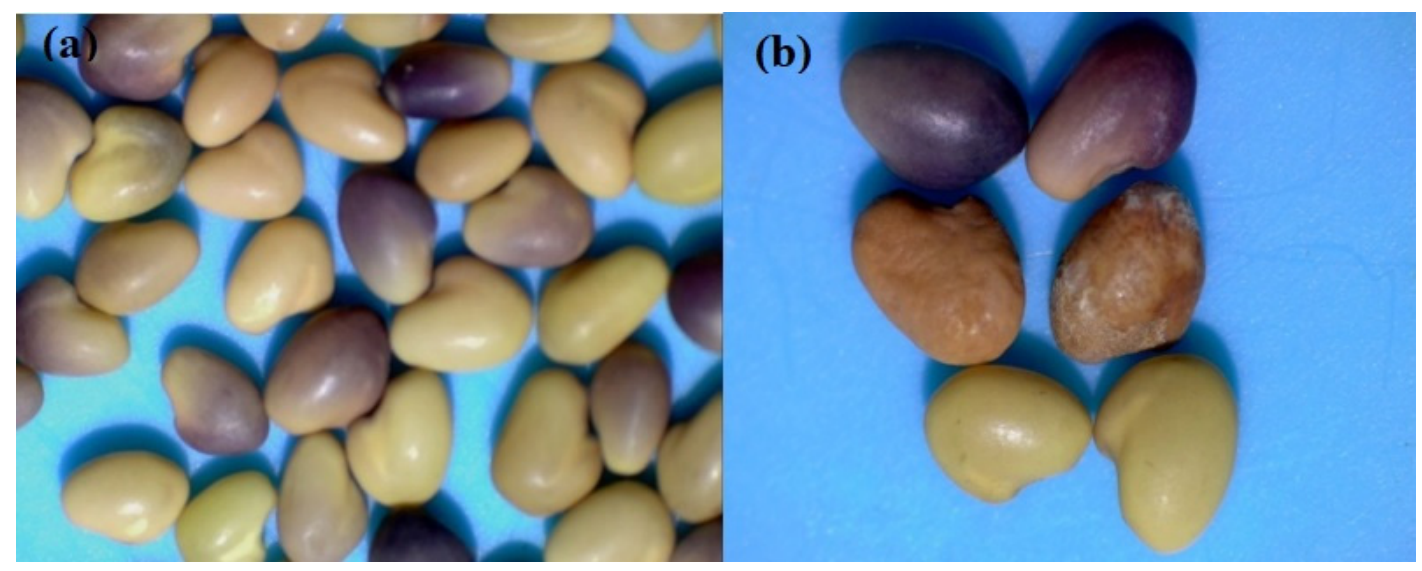

Figure 1. Variation of colors in a natural red clover seed lot (a); seeds of yellow, brown, and dark purple colors selected for the study (b).

Red clover seeds were treated with $\mathrm{CP}$ and EMF to increase their germination rate and stimulate seedling growth $[16,32]$. The equipment and treatment conditions have been described previously $[10,34]$. The conditions of seed treatment with radiofrequency (RF) EMF created at a frequency of $5.28 \mathrm{MHz}$ were as follows: The root-mean-square value of the magnetic component $H$ of EMF strength was $590 \mathrm{~A} / \mathrm{m}(B \approx 0.74 \mathrm{mT})$ with amplitude value $H *=\sqrt{2 H}$ of $835 \mathrm{~A} / \mathrm{m}(B \approx 1 \mathrm{mT})$, and the electric component $E$ was equal to $12.7 \mathrm{kV} / \mathrm{m}$ with amplitude value $E *=\sqrt{2 E}$ of $17.96 \mathrm{kV} / \mathrm{m}$. Seeds were placed at the center of the induction coil of the RF generator, and the treatment was performed for 10 and 15 min (these treatments are further abbreviated as EMF10 and EMF15, respectively) at atmospheric pressure and room temperature.

Seed treatments with $\mathrm{CP}$ were performed in a planar geometry reactor consisting of two plane-parallel, water-cooled copper electrodes (120 mm diameter) placed in a stainlesssteel hermetic chamber. Capacitively coupled RF discharge operated at $5.28 \mathrm{MHz}$ at a pressure of $200 \mathrm{~Pa}$, and RF input power density was $0.025 \mathrm{~W} / \mathrm{cm}^{3}$. An open sterile Petri dish with evenly dispersed seeds was placed on a grounded electrode and then air was pumped out from the chamber for 7 min aiming to achieve a pressure of 200 Pa before plasma ignition. CP treatment lasted 5 and $7 \mathrm{~min}$ (these treatments are further abbreviated as $\mathrm{CP} 5$ and $\mathrm{CP} 7$, respectively).

All experiments were performed in three replicates. Control, $\mathrm{CP}-$, and EMF-treated seeds were stored at room temperature $\left(19-22^{\circ} \mathrm{C}\right)$ until further investigation. Germination tests in vitro were performed four days after seed treatments. Seeds were evenly distributed on two layers of filter paper in 9-mm diameter plastic Petri dishes (three replicates of 50 seeds each) and watered with $3 \mathrm{~mL}$ of distilled water. Petri dishes with imbibed seeds were placed in a climatic chamber with automatic control of moisture $(60 \%)$, light, and temperature. Alternating light and temperature regimes were maintained in the chamber (darkness: $14{ }^{\circ} \mathrm{C}$ for $10 \mathrm{~h}$; light: $21^{\circ} \mathrm{C}$ for $14 \mathrm{~h}$ ). Seeds were provided with additional water 
in a Petri dish to prevent drying. Germinated seeds (as judged by the appearance of a visible $1 \mathrm{~mm}$ radicle) were counted every day until their number stopped increasing.

The germination results were analyzed using Richards' function [35] applied for the analysis of germinating seed population [36]. The following indices of germination kinetics were calculated: $\mathrm{V}_{\mathrm{i}}(\%)$, the final germination percentage indicating seed viability, Me (hours), the median germination time indicating the germination halftime of a seed lot or germination rate, $\mathrm{Qu}$ (hours), and the quartile deviation indicating the dispersion of germination time in a seed lot (half of the seeds with an average growth time germinated in the range $\mathrm{Me} \pm \mathrm{Qu}$ ) were calculated for control and treated groups as described earlier [10,12].

Part of the control and treated seeds of yellow and dark purple color was sown in rhizoboxes, and the emerged seedlings were cultivated for 5 weeks after sowing. For this, transparent plastic boxes (internal dimensions $15.2 \times 10.5 \times 3.2 \mathrm{~cm}$ ) with six drilled 3-mm holes in the bottom, filled with $700 \mathrm{~mL}$ of substrate, were used, as described recently in [32]. Eight seeds of red clover were sown per rhizobox (4 rhizoboxes with 28 seeds in total for one experimental group). The number of the emerged seedlings seeds per rhizobox varied from 6 to 4 . Rhizoboxes were placed in the climatic chamber under the conditions described above for the germination test. The seedlings were periodically watered to prevent drying.

Extracts of seed phytohormones in $85 \%$ methanol were prepared 4 days after treatment, at the same time as the germination test was started, as described earlier [15,37]. Plant hormones in the obtained abstracts were separated and quantified using high-performance liquid chromatography (HPLC). Agilent 1200 series HPLC system (Agilent Technologies Inc., Santa Clara, $\mathrm{CA}$, USA). Gibberellins $\left(\mathrm{GA}_{3}\right.$ and $\left.\mathrm{GA}_{7}\right)$ and abscisic acid (ABA) were detected at a wavelength of $254 \mathrm{~nm}$, while indole-3-acetic acid (IAA), indole-3-butyric acid (IBA), salicylic acid (SA), and zeatin (Z) were detected at $280 \mathrm{~nm}$. ABA, GA, IAA, IBA, SA, Z (Sigma-Aldrich, Taufkirchen, Germany), and GA 7 (TransMIT GmbH, Gießen, Germany) standards for identification and quantification of hormones were used.

Statistical analysis of the results was performed using Statistica 10 software. Mean values of various parameters between the control and treatment groups were compared using Student's $t$-tests for independent samples. Results were considered statistically significant at $p \leq 0.05$. The number of repetitions in experiments is indicated in the legends of figures or tables.

\section{Results}

\subsection{Effects on Germination In Vitro}

The germination test results in vitro for differently colored control and treated seeds of red clover cultivar 'Arimaiciai' are presented in Figure 2. The obtained germination curves showed that control yellow seeds germinated slower compared to all treated groups (Figure 2a). Simultaneously, the germination curve of the control brown purple seeds coincided with curves of EMF10 and EMF15 groups (Figure 2b) and the germination curve of the control dark purple seeds-with the curve of EMF15 groups. Regardless of the seed color, seeds in CP-treated groups germinated faster in comparison to the control, but the most apparent EMF effects on germination were observed for yellow seeds. The induced changes in germination were quantified by calculating the indices of germination kinetics $\mathrm{V}_{\mathrm{i}}, \mathrm{Me}$, and Qu for each seed group (Table 1).

There were no statistically significant differences in germination kinetic indices in the control seeds of the three studied colors (Table 1). The maximal germination percentage or viability of 'Arimaiciai' seeds $\left(\mathrm{V}_{\mathrm{i}}\right)$ was not affected by treatment with physical stressors. However, the treatments induced significant changes in the germination rate, and the extent of these changes depended on seed color. The germination rate of yellow seeds was increased by both CP and EMF: compared to the control, CP5, CP7, EML10, and EML15 decreased Me by $41,32,16$, and $11 \%$, respectively. The germination of dark purple seeds was stimulated by CP5, CP7, and EML10 by 31, 27, and 12\%, respectively, but EMF15 did not have an effect. The germination of brown seeds was not affected by EMF, while CP5 and CP7 increased germination rates by 22 and $26 \%$, respectively. 

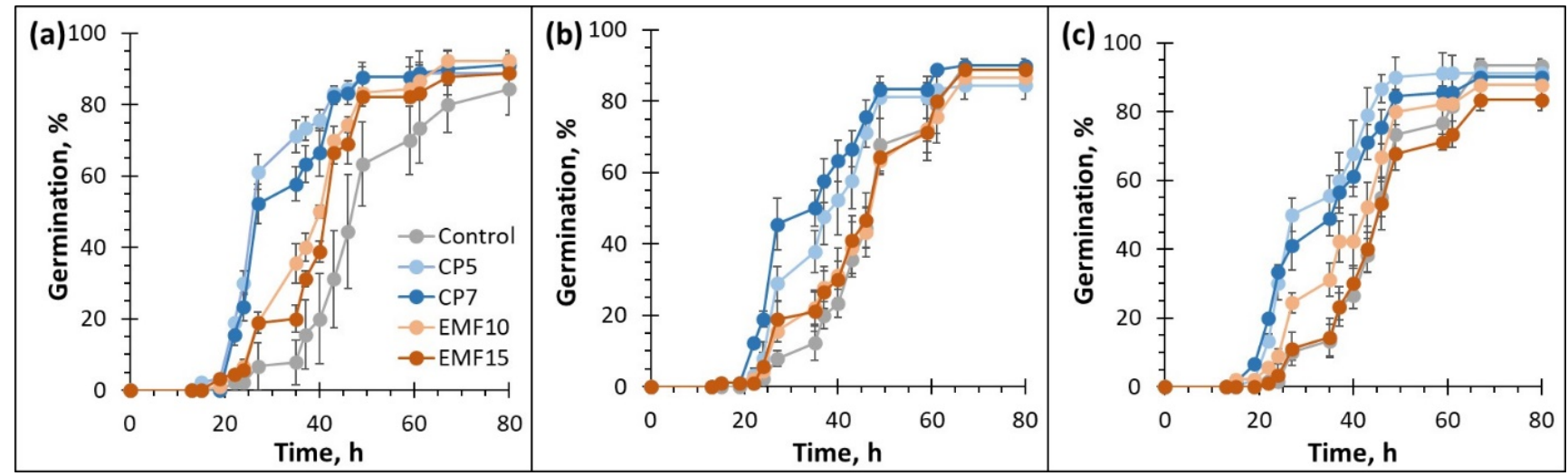

Figure 2. Germination dynamics of control and treated seeds of red clover-yellow (a), brown (b), and dark purple (c) seeds. Mean values of three replicates \pm standard error are presented. The number of seeds in each replicate was $50(n=3)$.

Table 1. Indices of germination kinetics of control and treated red clover seeds of different color.

\begin{tabular}{|c|c|c|c|c|c|c|}
\hline Seed Color & Germination Indices & Control & CP5 & $\mathrm{CP7}$ & EMF10 & EMF15 \\
\hline \multirow{3}{*}{ Yellow } & $\mathrm{V}_{\mathrm{i}}, \%$ & $84.4 \pm 7.3$ & $88.9 \pm 6.1$ & $91.1 \pm 2.9$ & $92.2 \pm 2.9$ & $89.0 \pm 1.1$ \\
\hline & $\mathrm{M}_{\mathrm{e}}, \mathrm{h}$ & $44.4 \pm 2.1$ & $26.0 \pm 1.5^{*}$ & $30.2 \pm 1.3 *$ & $37.6 \pm 0.9 *$ & $39.5 \pm 0.6$ * \\
\hline & $\mathrm{Qu}, \mathrm{h}$ & $5.1 \pm 1.0$ & $3.5 \pm 1.3$ & $6.6 \pm 0.4$ & $6.3 \pm 0.4$ & $5.3 \pm 0.5$ \\
\hline \multirow{3}{*}{ Brown } & $\mathrm{V}_{\mathrm{i}}, \%$ & $90.0 \pm 1.9$ & $84.4 \pm 4.0$ & $90.0 \pm 1.9$ & $86.7 \pm 3.3$ & $88.9 \pm 2.9$ \\
\hline & $\mathrm{M}_{\mathrm{e}}, \mathrm{h}$ & $45.8 \pm 2.0$ & $35.9 \pm 2.10 *$ & $34.1 \pm 0.8 *$ & $44.6 \pm 2.4$ & $44.1 \pm 1.7$ \\
\hline & $\mathrm{Qu}, \mathrm{h}$ & $6.9 \pm 1.1$ & $6,9 \pm 0.2$ & $7.5 \pm 1.20$ & $8.9 \pm 0.8$ & $8.5 \pm 0.7$ \\
\hline \multirow{3}{*}{ Dark purple } & $\mathrm{V}_{\mathrm{i}}, \%$ & $93.3 \pm 0.0$ & $91.1 \pm 4.0$ & $90.0 \pm 1.9$ & $87.8 \pm 4.8$ & $88.9 \pm 6.7$ \\
\hline & $\mathrm{M}_{\mathrm{e}}, \mathrm{h}$ & $43.8 \pm 0.1$ & $30.3 \pm 3.9^{*}$ & $31.9 \pm 1.1 *$ & $38.7 \pm 0.8$ * & $42.8 \pm 1.6$ \\
\hline & $\mathrm{Qu}, \mathrm{h}$ & $6.3 \pm 0.7$ & $4.9 \pm 1.6$ & $8.5 \pm 0.4 *$ & $7.5 \pm 0.5$ & $6.5 \pm 0.9$ \\
\hline
\end{tabular}

$\mathrm{V}_{\mathrm{i}}$, the final germination percentage; $\mathrm{M}_{\mathrm{e}}$, the median germination time; $\mathrm{Q}_{\mathrm{u}}$, the quartile deviation; results are presented as mean values \pm standard errors; ${ }^{*}$ significantly different from the control group $(p \leq 0.05)$.

\subsection{Effects on the Content of Phytohormones in Dry Seeds}

The content of phytohormones involved in the control of germination was determined, aiming to compare the amount of phytohormones and CP-induced changes in their amount in seeds of a different color. The obtained results of phytohormone analysis in red clover seeds are presented in Table 2.

The amount of ABA in control yellow seeds of the 'Arimaiciai' cultivar was almost 3 and 1.6 times lower compared to brown and dark purple seeds, respectively (Table 2). In addition, yellow seeds did not contain GA7, in contrast to control seeds of other colors. The level of GA3 was bellow detectable in extracts from all experimental groups. The amount of GA7 varied greatly depending on the seed color: In the control, the amount of GA7 in dark purple seeds was 49 times lower compared to that in brown seeds. The content of IAA in yellow seeds was 2.3-2.4 times higher in comparison to brown and dark purple seeds; yellow seeds contained $40 \%$ more $Z$ compared to brown seeds but $18 \%$ lower amount of $Z$ compared to dark purple seeds. Thus, the amounts of phytohormones controlling germination in control seeds significantly depended on seed color, although germination kinetics did not differ (Table 1).

Seed treatment with $\mathrm{CP}$ and EMF, along with stimulating germination in yellow seeds (Table 1), also increased the level of germination inhibitor ABA (CP5 and CP7 treatments-2.3 and 3.2 times; EMF10 and EMF15-2.3 and 1.6 times, respectively). In contrast, treatments did not change the amount of ABA in brown seeds, except for a slightly increased (14\%) ABA content observed in the CP5 group. However, the ABA amount in dark purple seeds was reduced by all treatments from 36 (CP5) to $51 \%$ (CP7). 
Table 2. Content of phytohormones $(\mu \mathrm{g} / \mathrm{g})$ in control and treated red clover seeds of different color.

\begin{tabular}{|c|c|c|c|c|c|c|c|}
\hline \multirow{2}{*}{ Seed Color } & \multirow{2}{*}{ Treatment } & \multicolumn{6}{|c|}{ Phytohormone } \\
\hline & & ABA & GA7 & IAA & IBA & $\mathbf{Z}$ & SA \\
\hline \multirow{5}{*}{ Yellow } & Control & $0.24 \pm 0.07^{\#}$ & $\mathrm{ND}^{\#}$ & $19.1 \pm 4.0^{\#}$ & $14.0 \pm 0.1$ & $0.83 \pm 0.01$ & $76.2 \pm 0.4^{\#}$ \\
\hline & CP5 & $0.54 \pm 0.03^{*}$ & ND & $9.7 \pm 1.9^{*}$ & $12.7 \pm 1.9$ & $0.51 \pm 0.07^{*}$ & $61.8 \pm 9.3^{*}$ \\
\hline & CP7 & $0.76 \pm 0.09 *$ & ND & $15.7 \pm 2.1$ & $15.9 \pm 0.2 *$ & $0.54 \pm 0.02 *$ & $70.7 \pm 1.6^{*}$ \\
\hline & EMF10 & $0.56 \pm 0.02 *$ & $87.7 \pm 3.3^{*}$ & $19.0 \pm 3.0$ & $12.9 \pm 0.6^{*}$ & ND & $48.6 \pm 1.1^{*}$ \\
\hline & EMF15 & $0.38 \pm 0.01 *$ & $84.0 \pm 2.0 *$ & $19.3 \pm 3.7$ & $11.3 \pm 0.5 *$ & ND & $46.3 \pm 1.3 *$ \\
\hline \multirow{5}{*}{ Brown } & Control & $0.71 \pm 0.04 \&$ & $363.9 \pm 9.0^{\&}$ & $8.2 \pm 1.8^{\&}$ & $15.2 \pm 0.6$ & $0.50 \pm 0.30$ & $66.3 \pm 3.3^{\&}$ \\
\hline & CP5 & $0.81 \pm 0.03 *$ & $187.5 \pm 5.7^{*}$ & $10.5 \pm 1.5$ & $15.0 \pm 0.6$ & $0.08 \pm 0.02 *$ & $69.3 \pm 3.9$ \\
\hline & CP7 & $0.73 \pm 0.04$ & $137.6 \pm 4.8^{*}$ & $9.3 \pm 4.4$ & $12.7 \pm 0.9 *$ & $0.60 \pm 0.20$ & $79.4 \pm 7.4^{*}$ \\
\hline & EMF10 & $0.74 \pm 0.01$ & $188.8 \pm 5.0 *$ & $8.6 \pm 0.2$ & $13.5 \pm 0.6^{*}$ & ND & $67.6 \pm 3.9$ \\
\hline & EMF15 & $0.72 \pm 0.02$ & $219.4 \pm 4.3 *$ & $8.3 \pm 0.4$ & $17.3 \pm 0.6$ & ND & $65.6 \pm 4.8$ \\
\hline \multirow{5}{*}{ Dark purple } & Control & $0.39 \underset{\& \&, \#}{ \pm} 0.10$ & $7.5 \pm 0.0^{\&, \#}$ & $8.0 \pm 1.0 \&$ & $16.3 \pm 0.9 \&$ & $0.70 \pm 0.07 \&$ & $92.6 \pm 5.3^{\&, \#}$ \\
\hline & CP5 & $0.25 \pm 0.06$ & $105.7 \pm 0.0$ * & $6.6 \pm 3.3$ & $14.2 \pm 0.4^{*}$ & $0.82 \pm 0.07$ & $72.2 \pm 2.8^{*}$ \\
\hline & $\mathrm{CP7}$ & $0.19 \pm 0.04 *$ & ND & $6.1 \pm 1.2$ & $11.7 \pm 2.4$ & $0.71 \pm 0.12$ & $63.5 \pm 12.3$ * \\
\hline & EMF10 & $0.23 \pm 0.02 *$ & $86.1 \pm 2.7^{*}$ & $6.8 \pm 1.3$ & $12.8 \pm 0.4^{*}$ & ND & $58.8 \pm 1.5^{*}$ \\
\hline & EMF15 & $0.24 \pm 0.03 *$ & $84.1 \pm 2.1 *$ & $7.9 \pm 1.2$ & $16.5 \pm 0.5$ & ND & $54.9 \pm 4.8^{*}$ \\
\hline
\end{tabular}

The means \pm SE of three replicates are presented $(n=3)$. Abbreviations: ABA, abscisic acid; GA3, gibberellin 3; GA7, gibberellin 7; GA, GA3 + GA7; IAA, indole-3-acetic acid; IBA, indole-3-butyric acid; ND, not detectable; SA, salicylic acid; Z, zeatin. * Significantly different from the control group $(p \leq 0.05)$; \& significantly different from the yellow seed control group; ${ }^{\#}$ significantly different from the brown seed control group.

The amount of germination-promoting GA7 hormone in the control group of yellow seeds was below the detectable level and seed treatments with EMF but not CP increased it. The high content of GA7 was found in brown control seeds, but it was significantly reduced by treatments (EMF15-1.7, CP5 and EMF10 - 1.9 and CP7-2.7 times). Seed treatments (except CP7) strongly increased GA7 only in dark purple seeds. GA3 level was below detectable in red clover 'Arimaiciai' cultivar seed extracts from all experimental groups.

Regardless of seed color, EMF treatments did not have an impact on the content of the germination inhibitor phytohormone IAA; but CP5 treatment reduced IAA content by 51\% in yellow seeds, whereas in brown seeds, it did not change the IAA content. Both CP5 and CP7 treatments reduced IAA amount in dark purple seeds by $18-24 \%$.

Zeatin level in yellow seeds was decreased by CP (30\%) but was not affected by CP in dark purple seeds, and it was 6.3 times reduced in brown seeds by CP5 only. The content of zeatin dropped below the detectable level in EMF-treated seeds of all three colors. The amount of stress hormone SA was reduced by CP5 and CP7 treatments in dark purple (20 and 29\%, respectively) and yellow seeds (18 and 6\%, respectively). In contrast, 20\% increased SA amount was detected in brown seeds treated with CP5. EMF treatments to a similar extent (36-41\%) reduced SA content in yellow and dark purple seeds but did not change it in brown seeds.

Thus, the amount of phytohormones in the control seeds of the red clover cultivar 'Arimaiciai' as well as their changes induced by seed treatments depended on seed color. However, the treatment effects on germination (Table 1) did not correlate with the observed shift in the balance of phytohormones (Table 2).

\subsection{Changes in the Early Growth of Red Clover Seedlings}

The length and weight of germinated seedlings was measured 7 days after sowing in order to estimate whether the effects of CP and EMF treatments on early seedling growth are dependent on seed color (Figure 3). 


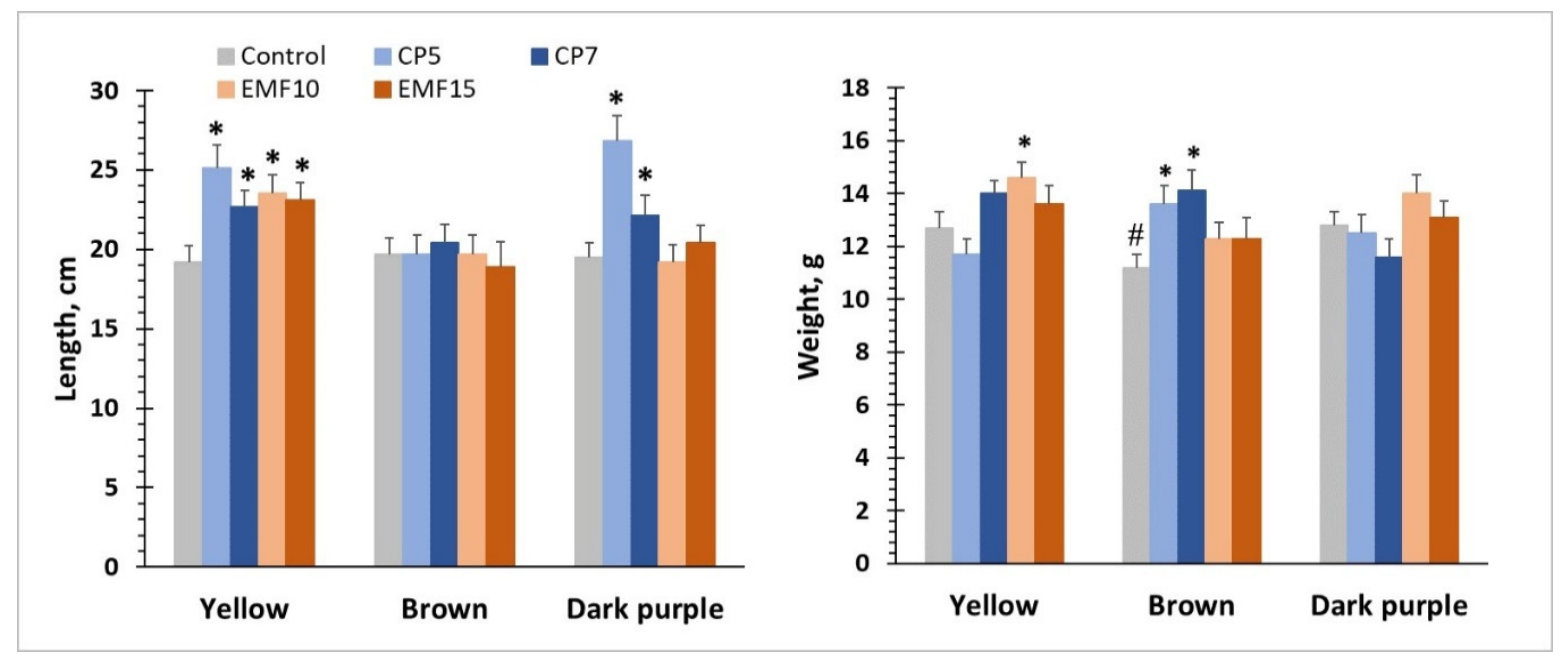

Figure 3. Morphometric parameters of red clover seedlings 7 days after sowing. The means \pm standard errors are presented $(n=24-29)$. * Significantly different from the control group $(p \leq 0.05) ;{ }^{\#}$ significantly different from seedlings growing from yellow seeds in the same treatment group $(p \leq 0.05)$.

The results showed that the effects of treatments on the early growth of red clover 'Arimaiciai' seedlings depended on seed color. Positive effects on germination (Table 1) were followed by improved growth parameters (Figure 3). The length of seedlings germinated from yellow seeds was larger in CP5-, CP7-, EMF10-, and EMF15-treated groups, compared to the control (by 31, 18,22, and 20\%, respectively), but the weight of seedlings increased by $15 \%$ only in EML10 group (Figure 3). An increase in length (but not weight) of seedlings from dark purple seeds by 37 and 13\% was observed in CP5 and CP7 groups, respectively. In contrast, treatments did not change the seedling length from brown seeds, although seedlings in C5 and C7 groups were 21 and 26\% heavier compared to the control.

\subsection{Changes in Seedling Growth and Nodulation}

The effects of seed treatments on the growth of red clover seedlings were also estimated at a later stage of seedling growth. For this, control and treated seeds were sown in rhizoboxes filled with a substrate and the emerged seedlings were cultivated for 5 weeks. Seedlings growing from seeds of brown color were not tested in this experiment because their relative amount in a seed lot was small compared to yellow and dark purple seeds. Seed treatment with EMF15 was also not performed since it did not affect the germination and early growth of seedlings from dark purple seeds. The results of morphometric analysis of red clover 'Arimaiciai' seedlings grown from yellow and dark purple seeds are presented in Figure 4.

The results revealed seed color-dependent differences in certain morphometric root parameters in control seedlings: roots were 30\% longer, but their weight was 3.1 times smaller, and the number of nodules was 12.5 times lower in seedlings growing from purple seeds compared to yellow seed seedlings. Seed treatments did not affect the height of the above-ground part of 'Arimaiciai' seedlings growing from yellow seeds but significantly increased root length: CP5, CP7, and EMF10 by 39, 42, and 36\%, respectively (Figure 4a). The above-ground part's weight was not affected by CP5 and EMF10, but CP7 decreased it by $34 \%$ compared to the control. Although the mean root weight was changed by seed treatments, due to the high scatter of results in the control group, the only significant effect was reduced root weight in the CP7 group (by 54\%). The number of leaves was not affected by seed treatments in seedlings growing from yellow seeds, but the number of nodules was doubled by EMF10 (Figure 4a), while the effects of CP treatments on the number of nodules were not statistically significant. 


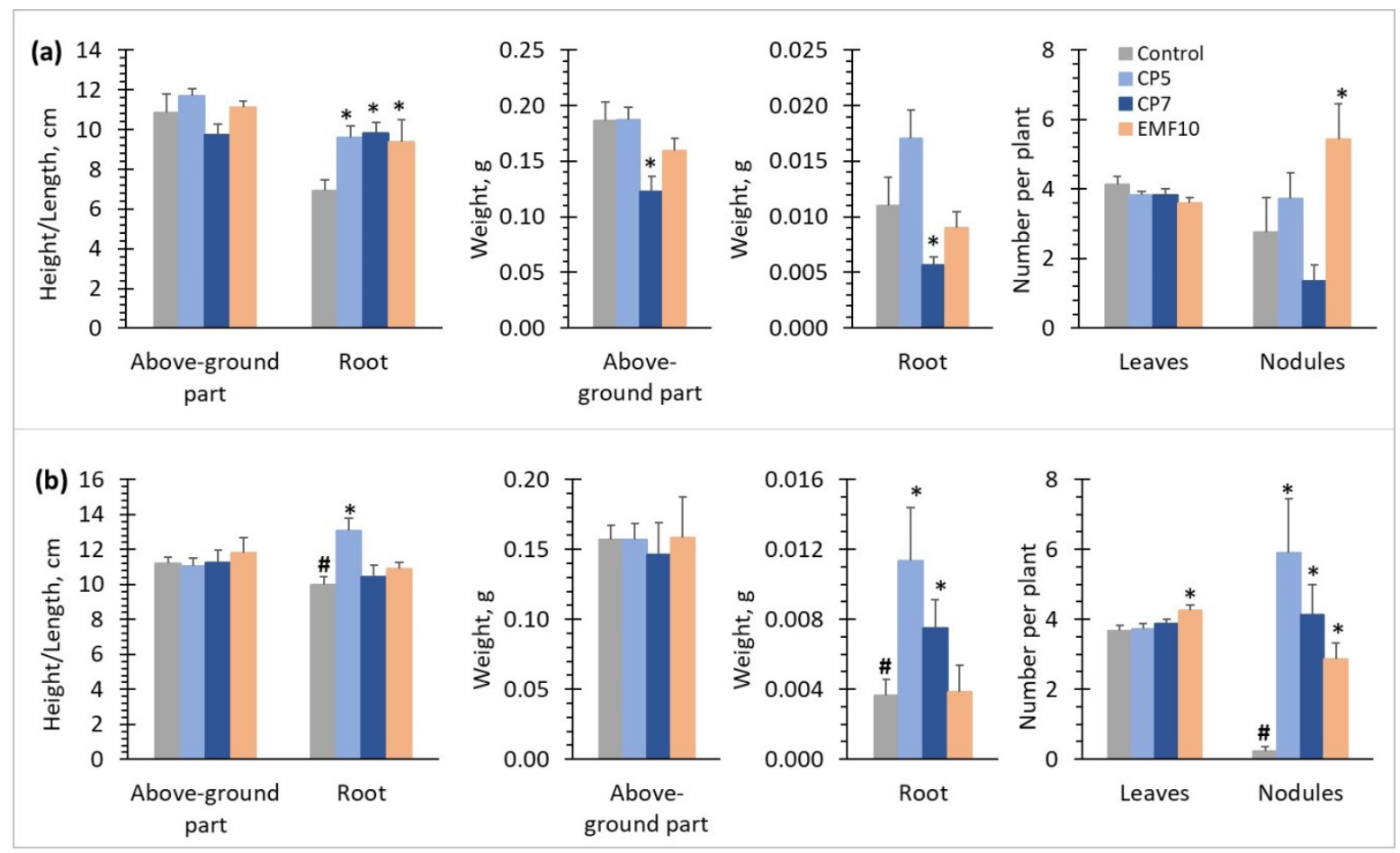

Figure 4. Morphometric parameters of red clover seedlings grown in rhizoboxes 5 weeks after sowing. Seedlings were grown from yellow (a) and dark purple (b) seeds. Mean values \pm standard error are presented. The number of seedlings in the experimental group was $n=19-23$. * Significantly different from the control group $(p \leq 0.05)$; ${ }^{\#}$ significantly different from seedlings growing from control yellow seeds $(p \leq 0.05)$.

Treatments did not change the height of the above-ground part of seedlings growing from dark purple seeds (Figure 4b), but in contrast to seedlings from yellow seeds, CP7 and EMF10 did not affect the root length, and only CP5 increased it by $31 \%$. Seed treatments did not affect the weight of the above-ground part of the seedlings from dark purple seeds (Figure $4 \mathrm{~b}$ ), but the root weight increased several folds in CP treatment groups (3-fold and more than 2-fold in CP5 and CP7 groups, respectively) compared to control. EMF10 did not change the root weight but increased the number of leaves by $16 \%$ (Figure $4 \mathrm{~b}$ ). Seed treatments exerted a strong positive effect on the number of nodules: CP5 increased the number of nodules by 27, CP7 by 19, EMF10 by 13 times (Figure $4 \mathrm{~b}$ ). As a result, the mean number of root nodules in dark purple seed seedlings in the CP7 group was 3.3 times larger compared with the number of nodules in the roots of CP7-treated yellow seed seedlings $(p<0.05)$, while the difference between seedlings grown from differently colored seeds exposed to CP5 treatment was not statistically significant. Thus, $\mathrm{CP}$ treatments strongly improved nodulation in seedlings grown from dark purple seeds. EMF10 treatment had a strong positive effect on nodulation activity in seedlings grown from seeds of both colors, but the number of nodules in yellow seeds seedlings was 1.76 times larger compared to dark purple seed seedlings $(p<0.05)$.

\section{Discussion}

Seed color formation is genetically regulated. The color of red clover seeds is determined by two gene loci [38], and yellow seed coats are homozygous recessive at both, while a dominant allele at either locus imparts a light purple color and dominant alleles at both loci result in dark purple seed coats. It has been determined that the pleiotropic gene locus controls the dormancy and pigment traits in red rice by regulating ABA and flavonoid biosynthetic pathways, respectively [39]. The relationship between seed germination and coat color was reported for legumes, e.g., physical dormancy (often called hard seededness) correlates with the amount of phenolic pigments and dark seed color [21]. In contrast to 
previous studies [30,31], we did not obtain a clear difference in germination kinetics of yellow seeds compared to dark purple or brown seeds of red clover (Table 1); at least the germination of 'Arimaiciai' cultivar seeds was not dependent on seed color in the control group. However, the effects of seed treatments with $\mathrm{CP}$ and EMF on germination and seedling growth were dependent on seed color. Germination of yellow seeds was stimulated by both durations of CP (CP5, CP7) and EMF (EMF10, EMF15) treatments, while brown seeds germinated faster only in $\mathrm{CP}$ but not in EMF-treated groups. The response of dark purple seeds was intermediate between yellow and brown seeds (EMF15 did not stimulate germination), and the extent of stimulation was lower compared to that in yellow seeds.

One of the possible explanations for such differences may be related to the content of pigments as well as other phenolics in seeds of different color. It has been established that production of hydrogen peroxide and other ROS species plays a key role in activation of germination processes so that insufficient amounts of $\mathrm{H}_{2} \mathrm{O}_{2}$ may cause delay in germination $[40,41]$. We have demonstrated that changes in germination of Norway spruce seeds induced by $\mathrm{CP}$ and EMF are related to modulated production of $\mathrm{H}_{2} \mathrm{O}_{2}$ in germinating seeds [26]. Therefore, it is possible to hypothesize that treatment induced changes in $\mathrm{H}_{2} \mathrm{O}_{2}$ generation in brown and dark purple seeds are "shielded" due to higher amount of ROS scavengers compared to yellow seeds (having less pigments).

Different effects of $\mathrm{CP}$ on germination of color morphs may be related also to different absorption of CP generated UV light in seeds of different color. Low-temperature nonequilibrium $\mathrm{CP}$ in the air at a low pressure used in our study generates radiation in a spectral range from UV $(220 \mathrm{~nm})$ up to near infrared $(1100 \mathrm{~nm})$ [32]. A weak UV radiation in the range of $220-350 \mathrm{~nm}$ is attributed to the molecular bands of oxygen-based and nitrogenbased species $(\mathrm{NO}, \mathrm{OH})$ formed in air plasma. Thus, $\mathrm{CP}$-treated seeds were exposed to UVC, $\mathrm{UVB}$, and UVB radiation and the effects of UV radiation on seed germination cannot be excluded. However, the reports on the effects of UV on germination are controversial [42]. Despite numerous reports on stimulation of seed germination by UVB and UVA (when UV is applied without $\mathrm{CP}$ ), some studies present evidences that contribution of UV radiation to the effects of CP treatments on germination is negligible [43]. Phytochromes are light sensing molecules involved in the control of plant germination and morphogenesis [44]. Plant cells perceive UV-B radiation by the photoreceptor UVR8 which is well studied in Arabidopsis thaliana [45]; however, the information on the amount of UVR8 on red clover seeds of different color is not available.

The obtained results are in line with recently reported observations that radish $(R$. sativus) seeds of different coat colors show different responses to atmospheric DBD plasma treatment $[27,28]$. In this study, we used low-pressure RF plasma. This study also confirmed the finding of [28], i.e., that the content of phytohormones in seeds controlling the germination is dependent on the seed color. We found significant differences in the content of phytohormones in control seeds of red clover of three selected colors (yellow, brown, and dark purple, excluding intermediate versions) (Table 2). However, the effects of $\mathrm{CP}$ and EMF treatments on germination (Table 1) did not correlate with the observed shift in the balance of phytohormones. The alleviation of physiological dormancy and stimulation of germination are associated with an increase in the ratio GA/ABA $[40,46]$, but CP-induced decrease in the amount of ABA was observed in dark purple seeds only, whereas ABA was increased after $\mathrm{CP}$ treatment in yellow or brown (CP5 group) seeds (Table 2). The amount of GA7 was below the detectable level in the control yellow seeds and CP increased GA7 amounts. Possibly, other biologically important gibberellins (detectable by MS method only) may be characteristic of the yellow seeds of the 'Arimaiciai' cultivar. The content of GA7 in brown control seeds was reduced by CP treatments; CP5 increased GA7 only in dark purple seeds. Effects of EMF treatments on ABA and GA7 content were also dependent on seed color, but irrespective of seed color, EMF induced a strong decrease in $\mathrm{Z}$ and SA content.

Although physical dormancy is typical for legumes, including red clover, we have reported previously that $\mathrm{CP}$ and EMF treatments induced GA/ABA increase in dry seeds 
of the red clover cultivar 'Sadunai' [32]. However, the amount of ABA in the control seeds of 'Sadunai' [32] was from 6.6 to 20-fold larger compared to brown and yellow 'Arimaiciai' seeds, respectively (Table 2); thus, control seeds used for the experiment in this study did not exert signs of physiological dormancy. Therefore, treatments did not induce changes in the balance of phytohormones characteristic for the break in physiological dormancy $[40,46]$. In such situations, seed treatments may act by changing the properties of the seed coat. Nevertheless, a higher amount of ABA in dark purple seeds compared to yellow ones may be explained by the ability of proanthocyanidins to promote ABA synthesis [47].

The effects of seed treatments on early seedling growth were dependent on seed color but did not always correlate with the effect of stressors on seed germination. Treatments increased the length of 'Arimaiciai' seedlings growing from yellow and dark purple seeds, but the weight of seedlings from brown seeds. In seedlings grown for 5 weeks (Figure 4), treatments induced changes only in the morphometric parameters of the roots but not in the above-ground part. In the control group, roots of seedlings from dark-purple seeds were longer but had smaller weight compared to yellow seed seedlings, but CP treatments increased their weight. The largest coat color-dependent difference was observed in the number of root nodules, which was particularly low in the roots of dark purple seed seedlings; however, both CP and EMF treatment effectively (13-27 times) increased their nodulation activity. As a result, the seed color-dependent difference in treated seedlings was much less (EMF15 group), or nodulation in dark purple seed seedlings even became higher (CP7 group) compared to the yellow seed seedlings. Thus, the results of this study are in line with previously reported findings that CP treatments activate root nodulation in soybean [48] and red clover [32]. In addition, the dependence of the effect on seed coat color was demonstrated.

The molecular mechanisms underlying the effects of seed treatment with $\mathrm{CP}$ are currently under intensive research (see the most recent reviews [1-3,42]); however, numerous key questions still remain to be established. Nevertheless, the body of the accumulated experimental evidence on the persistence of effects in time provides background for the deeper insight on the consequences of stress experienced by the seed. Numerous reports indicate that seed treatment with $\mathrm{CP}$ induces multiple adaptive changes observable on later stages of plant vegetation and leading to changes in agronomic plant performance. It has been established that CP induces chemical modifications in seed coats, leading to increased wettability [49] and the seed EPR signal [26-28]. Rapid changes in the amounts of phytohormones [15,32,37,50], modified DNA methylation in dry seeds [51], changes of protein expression, and enzymatic activities underlying the effects on germination have been demonstrated. Although EMF treatment is less complex and aggressive stressor compared to $\mathrm{CP}$, the observed effects of seed treatments with EMF have many similarities to those induced by CP: EMF increased EPR signal [26], changed the balance of phytohormones [15,32] in dry seeds, and increased ROS production in germinating seeds [26]. Seed treatments with CP and EMF are further followed by changes in DNA methylation [52], protein expression and numerous enzymatic activities in tissues of growing seedlings [6,47] including proteins that are important for photosynthetic activity and antioxidant defense. Substantial changes in plant associated microbiome due to sunflower seed treatment with $\mathrm{CP}$ have been reported [53]. Much evidence indicates that secondary metabolism is activated in plants growing from the CP- or EMF-treated seeds $[12,16,34,54]$, and that may lead to increased plant fitness and improved growth due to stimulated communication with beneficial microorganisms $[32,48]$. It remains to be determined which of these mechanisms are involved in the improvement of agricultural performance of different plants.

The obtained results revealed that the effects of pre-sowing treatment of red clover seeds with CP and EMF on germination and seedling growth depend on seed coat color. The extent of variability of seed color in red clover or other plant species exerting seed color polymorphism may depend on the variety (cultivar) or environmental conditions for seed development [29]. Therefore, such dependence may contribute to the variation, masking, 
or poor reproducibility of the studied CP or EMF treatment effects. It might be reasonable to select seeds by color for certain experimental studies to minimize variation and improve understanding of the molecular mechanisms underlying the effects of treatments.

Author Contributions: Conceptualization, V.M., I.F., methodology, Z.N., R.Z., V.L.; investigation, A.I., L.D.-F., R.Z., Z.N.; data curation, A.I.; writing—original draft preparation, V.M.; writing-review and editing, A.I., R.Z., Z.N., V.M., L.D.-F., V.L., I.F.; visualization, Z.N.; supervision, V.M., I.F.; project administration, V.M. All authors have read and agreed to the published version of the manuscript.

Funding: This research was funded by the Lithuanian Research Council grant nos. S-LB-19-3, S-LJB-19-2, and F19LITG-008 from the Belarusian Republican Foundation for Fundamental Research.

Acknowledgments: We are grateful for Vaclovas Stukonis from the Institute of Agriculture, Lithuanian Research Centre for Agriculture and Forestry for providing seeds of red clover cultivar 'Arimaiciai'.

Conflicts of Interest: The authors declare no conflict of interest.

\section{References}

1. Attri, P.; Ishikawa, K.; Okumura, T.; Koga, K.; Shiratani, M. Plasma agriculture from laboratory to farm: A review. Processes 2020, 8, 1002. [CrossRef]

2. Staric, P.; Vogel-Mikuš, K.; Mozetic, M.; Junkar, I. Effects of nonthermal plasma on morphology, genetics and physiology of seeds: A Review. Plants 2020, 9, 1736. [CrossRef]

3. Holubová, L.; Kyzek, S.; Durovcová, I.; Fabová, J.; Horváthová, E.; Ševcovicová, A.; Gálová, E. Non-thermal plasma-a new green priming agent for plants? Int. J. Mol. Sci. 2020, 21, 9466. [CrossRef]

4. Maffei, M.E. Magnetic field effects on plant growth, development and evolution. Front. Plant Sci. 2014, 5, 1-15. [CrossRef] [PubMed]

5. Pietrusziewski, S.; Martinez, E. Magnetic field as a method of improving the quality of sowing material: A review. Int. Agrophys. 2015, 29, 377-389. [CrossRef]

6. Kaur, S.; Vian, A.; Chandel, S.; Singh, H.P.; Batish, D.R.; Kohli, R.K. Sensitivity of plants to high frequency electromagnetic radiation: Cellular mechanisms and morphological changes. Rev. Environ. Sci. Biotechnol. 2021, 20, 55-74. [CrossRef]

7. Azharonok, V.; Goncharik, S.V.; Filatova, I.I.; Shik, A.S.; Antonyuk, A.S. The effect of the high frequency electromagnetic treatment of the sowing material for legumes on their sowing quality and productivity. Surf. Eng. Appl. Electrochem. 2009, 45, 317-327. [CrossRef]

8. Filatova, I.I.; Azharonok, V.V.; Goncharik, S.V.; Lyushkevich, V.A.; Zhukovsky, A.G.; Gadzhieva, G.I. Effect of RF plasma treatment on the germination and phytosanitary state of seeds. J. Appl. Spectrosc. 2014, 81, 250-256. [CrossRef]

9. Stolarik, T.; Henselova, M.; Martinka, M.; Novak, O.; Zahoranova, A.; Cernak, M. Effect of low temperature plasma on the structure of seeds, growth and metabolism of endogenous phytohormones in pea (Pisum sativum L.). Plasma Chem. Plasma Proc. 2015, 35, 659-676. [CrossRef]

10. Mildaziene, V.; Pauzaite, G.; Malakauskiene, A.; Zukiene, R.; Nauciene, Z.; Filatova, I.; Azharonok, V.; Lyushkevich, V. Response of perennial woody plants to seed treatment by electromagnetic field and low-temperature plasma. Bioelectromagnetics 2016, 37, 536-548. [CrossRef] [PubMed]

11. Koga, K.; Thapanut, S.; Amano, T.; Seo, H.; Itagaki, N.; Hayashi, N.; Shiratani, M. Simple method of improving harvest by nonthermal air plasma irradiation of seeds of Arabidopsis thaliana (L.). Appl. Phys. Express 2016, 9, 016201. [CrossRef]

12. Mildažienè, V.; Paužaite, G.; Naučienè, Z.; Malakauskiene, A.; Žūkienè, R.; Januškaitienè, I.; Jakštas, V.; Ivanauskas, L.; Filatova, I.; Lyushkevich, V. Pre-sowing seed treatment with cold plasma and electromagnetic field increases secondary metabolite content in purple coneflower (Echinacea purpurea) leaves. Plasma Process. Polym. 2018, 14, 1700059. [CrossRef]

13. Jiang, J.; Lu, Y.; Li, J.; Li, L.; He, X.; Shao, H.; Dong, S. Effect of cold plasma treatment on seed germination and growth of wheat. PLoS ONE 2014, 9, e97753. [CrossRef]

14. De Groot, G.J.J.A.; Hundt, A.; Murphy, A.B.; Bange, M.P.; Mai-Prochnow, A. Cold plasma treatment for cotton seed germination improvement. Sci. Rep. 2018, 8, 14372. [CrossRef]

15. Degutytė-Fomins, L.; Paužaitė, G.; Žukienè, R.; Mildažienè, V.; Koga, K.; Shiratani, M. Relationship between cold plasma treatment-induced changes in radish seed germination and phytohormone balance. Jpn. J. Appl. Phys. 2020, 59, SH1001. [CrossRef]

16. Mildažienè, V.; Paužaitè, G.; Naučienè, Z.; Žūkienè, R.; Malakauskienè, A.; Norkevičienė, E.; Šlepetienè, A.; Stukonis, V.; Olšauskaite, V.; Padarauskas, A.; et al. Effect of seed treatment with cold plasma and electromagnetic field on red clover germination, growth and content of major isoflavones. J. Phys. D Appl. Phys. 2020, 53, 264001. [CrossRef]

17. Imbert, E. Ecological consequences and ontogeny of seed heteromorphism. Perspect. Plant Ecol. 2002, 5, 13-36. [CrossRef]

18. Matilla, A.; Matilla, A.; Gallardo, M.; Puga-Hermida, M.I. Structural, physiological and molecular aspects of heterogeneity in seeds: A review. Seed Sci. Res. 2005, 15, 63-76. [CrossRef] 
19. Baskin, C.C.; Baskin, J.M. Seeds: Ecology, Biogeography, and, Evolution of Dormancy and Germination, 2nd ed.; Academic Press: Lexington, KY, USA, 2014; pp. 101-116.

20. Finch-Savage, W.E.; Leubner-Metzger, G. Seed dormancy and the control of germination. New Phytol. 2006, 171, 501-523. [CrossRef] [PubMed]

21. Smykal, P.; Vernoud, V.; Blair, M.W.; Soukup, A.; Thompson, R.D. The role of the testa during development and in establishment of dormancy of the legume seed. Front. Plant Sci. 2014, 5, 351.

22. Cechová, M.; Válková, M.; Hradilová, I.; Soukup, A.; Janská, A.; Smýkal, P.; Bednář, P. Towards better understanding of pea seed dormancy using laser desorption/ionization mass spectrometry. Int. J. Mol. Sci. 2017, 18, 2196. [CrossRef] [PubMed]

23. Hradilová, I.; Duchoslav, M.; Brus, J.; Pechanec, V.; Hýbl, M.; Kopecký, P.; Smržová, L.; Štefelová, N.; Vaclávek, T.; Michael, B.; et al. Variation in wild pea (Pisum sativum subsp. elatius) seed dormancy and its relationship to the environment and seed coat traits. Peer J. 2019, 7, e6263. [CrossRef]

24. Appelhagen, I.; Thiedig, K.; Nordholt, N.; Schmidt, N.; Huep, G.; Sagasser, M.; Weisshaar, B. Update on transparent testa mutants from Arabidopsis thaliana: Characterisation of new alleles from an isogenic collection. Planta 2014, 240, 955. [CrossRef]

25. Lepiniec, L.; Debeaujon, I.; Routaboul, J.-M.; Baudry, A.; Pourcel, L.; Nesi, N.; Caboche, M. Genetics and biochemistry of seed flavonoids. Ann. Rev. Plant Biochem. 2006, 57, 405-430. [CrossRef]

26. Paužaitè, G.; Malakauskiene, A.; Naučienè, Z.; Žūkienė, R.; Filatova, I.; Lyushkevich, V.; Azarko, I.; Mildažienė, V. Changes in Norway spruce germination and growth induced by pre-sowing seed treatment with cold plasma and electromagnetic field: Short-term versus long-term effects. Plasma Process. Polym. 2018, 14, 1700068. [CrossRef]

27. Koga, K.; Attri, P.; Kamataki, K.; Itakagi, N.; Shiratani, M.; Mildažienè, V. Impact of radish sprouts seeds coat color on the electron paramagnetic resonance signals after plasma treatment. Jpn. J. Appl. Phys. 2020, 59, SHHF01. [CrossRef]

28. Attri, P.; Ishikawa, K.; Okumura, T.; Koga, K.; Shiratani, M.; Mildaziene, V. Impact of seed color and storage time on the radish seed germination and sprout growth in plasma agriculture. Sci. Rep. 2021, 11, 2539. [CrossRef]

29. Bortnem, R.; Boe, A. Color index for red clover seed. Crop Sci. 2003, 43, 2279. [CrossRef]

30. Velijevic, N.; Strbanovic, R.; Postic, D.; Stanisavljevic, R.; Djukanovic, L. Effects of seed coat colour on the seed quality and initial seedling growth of red clover cultivars (Trifolium pratense). J. Process. Energy Agric. 2017, 21, 174. [CrossRef]

31. Atis, I.; Atak, M.; Can, E.; Mavi, K. Seed coat color effects on seed quality and salt tolerance of red clover (Trifolium pratense). Int. J. Agric. Biol. 2011, 13, 363-368.

32. Mildažienè, V.; Ivankov, A.; Paužaitè, G.; Naučienè, Z.; Žūkienè, R.; Degutytè-Fomins, L.; Pukalskas, A.; Venskutonis, P.R.; Filatova, I.; Lyushkevich, V. Seed treatment with cold plasma and electromagnetic field induces changes in red clover root growth dynamics, flavonoid exudation, and activates nodulation. Plasma Process. Polym. 2020, 17, 2000160.

33. Hunt, R.W.; Pointer, M. Measuring Colour, 4th ed.; John Wiley \& Sons, Ltd.: Chichester, UK, 2011.

34. Ivankov, A.; Nauciene, Z.; Zukiene, R.; Degutyte-Fomins, L.; Malakauskiene, A.; Kraujalis, P.; Venskutonis, P.R.; Filatova, I.; Lyushkevich, V.; Mildaziene, V. Changes in growth and production of non-psychotropic cannabinoids induced by pre-sowing treatment of hemp seeds with cold plasma, vacuum and electromagnetic field. Appl. Sci. 2020, 10, 8519. [CrossRef]

35. Richards, F.J. A flexible growth function for empirical use. J. Exp. Bot. 1959, 10, 290-300. [CrossRef]

36. Hara, Y. Calculation of population parameters using Richards function and application of indices of growth and seed vigor to rice plants. Plant Prod. Sci. 1999, 2, 129-135. [CrossRef]

37. Zukiene, R.; Nauciene, Z.; Januskaitiene, I.; Pauzaite, G.; Mildaziene, V.; Koga, K.; Shiratani, M. DBD plasma treatment induced changes in sunflower seed germination, phytohormone balance, and seedling growth. Appl. Phys. Express 2019, 12, 126003. [CrossRef]

38. Nijdam, F.E. Kruisingen met Trifolium pratense L. Genetica 1937, 14, 161-278. [CrossRef]

39. Gu, X.; Foley, M.E.; Horvath, D.P.; Anderson, J.V.; Feng, J.; Zhang, L.; Chen, Z. Association between seed dormancy and pericarp color is controlled by a pleiotropic gene that regulates abscisic acid and flavonoid synthesis in weedy red rice. Genetics 2011, 189, 1515-1524. [CrossRef] [PubMed]

40. Oracz, K.; Karpinski, S. Phytohormones signaling pathways and ROS involvement in seed germination. Front. Plant Sci. 2016, 7, 864. [CrossRef] [PubMed]

41. Wojtyla, Ł.; Lechowska, K.; Kubala, S.; Garnczarska, M. Different modes of hydrogen peroxide action during seed germination. Front. Plant Sci. 2016, 7, 66. [CrossRef]

42. Waskow, A.; Howling, A.; Furno, I. Mechanisms of plasma-seed treatments as a potential seed processing technology. Front. Phys. 2021, 9, 617345. [CrossRef]

43. Sarinont, T.; Amano, T.; Attri, P.; Koga, K.; Hayashi, N.; Shiratani, M. Effects of plasma irradiation using various feeding gases on growth of Raphanus sativus L. Arch. Biochem. Biophys. 2016, 605, 129-140. [CrossRef]

44. Legris, M.; Ince, Y.Ç.; Fankhauser, C. Molecular mechanisms underlying phytochrome-controlled morphogenesis in plants. Nat. Commun. 2019, 10, 5219. [CrossRef] [PubMed]

45. Heijde, M.; Ulm, R. UV-B photoreceptor-mediated signalling in plants. Trends Plant Sci. 2012, 17, 230-237. [CrossRef]

46. Shu, K.; Liu, X.-D.; Xie, Q.; He, Z.-H. Two faces of one seed: Hormonal regulation of dormancy and germination. Mol. Plant 2016, 9, 34-45. [CrossRef] [PubMed]

47. Jia, L.; Wu, Q.; Ye, N.; Liu, R.; Shi, L.; Xu, W.; Zhang, J. Proanthocyanidins inhibit seed germination by maintaining a high level of abscisic acid in Arabidopsis thaliana F. J. Integr. Plant Biol. 2012, 54, 663. [CrossRef] 
48. Pérez-Pizá, M.C.; Cejas, E.; Prevosto, C.L.; Mancinelli, B.; Santa-Cruz, D.; Yannarelli, G.; Balestrasse, K. Enhancement of soybean nodulation by seed treatment with non-thermal plasmas. Sci. Rep. 2020, 10, 4917. [CrossRef] [PubMed]

49. Bormashenko, E.; Grynyov, R.; Bormashenko, Y.; Drori, E. Cold Radio frequency Plasma Treatment Modifies Wettability and Germination Speed of Plant Seeds. Sci. Rep. 2012, 12, 741. [CrossRef] [PubMed]

50. Mildažienè, V.; Aleknavičiūtè, V.; Žūkienè, R.; Paužaitè, G.; Naučienè, Z.; Filatova, I.; Lyushkevich, V.; Haimi, P.; Tamošiūnè, I.; Baniulis, D. Treatment of Common sunflower (Helianthus annus L.) seeds with radio-frequency electromagnetic field and cold plasma induces changes in seed phytohormone balance, seedling development and leaf protein expression. Sci. Rep. 2019, 9, 6437. [CrossRef]

51. Suriyasak, S.; Hatanaka, K.; Tanaka, H.; Okumura, T.; Yamashita, D.; Attri, P.; Koga, K.; Shiratani, M.; Hamaoka, N.; Ishibashi, Y. Alterations of DNA Methylation Caused by Cold Plasma Treatment Restore Delayed Germination of Heat-Stressed Rice (Oryza sativa L.) Seeds. ACS Agric. Sci. Technol. 2021, 1, 5-10. [CrossRef]

52. Zhang, J.J.; Jo, J.O.; Huynh, D.L.; Mongre, R.K.; Ghosh, M.; Singh, A.K.; Lee, S.B.; Mok, Y.S.; Hyuk, P.; Jeong, D.K. Growth-inducing effects of argon plasma on soybean sprouts via the regulation of demethylation levels of energy metabolism-related genes. Sci. Rep. 2017, 7, 41917. [CrossRef]

53. Tamošiūnè, I.; Gelvonauskienè, D.; Haimi, P.; Mildažienè, V.; Koga, K.; Shiratani, M.; Baniulis, D. Cold plasma treatment of sunflower seeds modulates plant-associated microbiome and stimulates root and lateral organ growth. Front. Plant Sci. 2020, 11, 568924. [CrossRef] [PubMed]

54. Iranbakhsh, A.; Oraghi Ardebili, Z.; Molaei, H.; Oraghi Ardebili, N.; Amini, M. Cold plasma up-regulated expressions of WRKY1 transcription factor and genes involved in biosynthesis of cannabinoids in hemp (Cannabis sativa L.). Plasma Chem. Plasma Proc. 2020, 40, 527-537. [CrossRef] 